\title{
EXECUTIVE FUNCTIONING IN PATIENTS WITH BLEPHAROSPASM IN COMPARISON WITH PATIENTS WITH HEMIFACIAL SPASM
}

\author{
Fernando Machado Vilhena Dias', Flávia C.P. Doyle ${ }^{2}$, Arthur Kummer', \\ Francisco Cardoso ${ }^{4}$, Paulo Caramelli, Antônio Lúcio Teixeira ${ }^{4}$
}

\begin{abstract}
Background: Non-motor symptoms have been described in primary dystonia, but the results on cognitive impairment in this condition are discordant. Blepharospasm (BM) is a type of primary focal dystonia characterized by recurrent and involuntary eye blinking. Hemifacial spasm (HS), a condition with different pathophysiology, constitutes an adequate control group when investigating non-motor disturbances in BM. Objective: To compare the performance of patients with BM and HS in the Frontal Assessment Battery (FAB). Method: Twenty-two patients with BM and 29 patients with HS were submitted to the FAB and the MiniMental State Examination (MMSE). FAB scores were compared between the two groups. Correlations between $F A B$ and sociodemographic and clinical variables were calculated. Results: BM group was not different from HS in relation to gender, age, length of symptoms, educational level and performance in the MMSE. FAB scores were also similar in both groups. FAB scores correlated negatively with age and positively with educational level and MMSE scores. Conclusion: Executive functioning as assessed by FAB is not altered in BM in comparison with HS.
\end{abstract}

KEY WORDS: dystonia, blefarospam, hemifacial spasm, executive function.

\section{Funções executivas em pacientes com blefaroespasmo em comparação a pacientes com espasmo hemifacial}

Resumo - Introdução: Alterações não-motoras são descritas na distonia primária, embora sejam conflitantes os resultados sobre prejuizo cognitivo nessa condição. Blefaroespasmo (BE) é um tipo de distonia primária focal caracterizada por contrações recorrentes e involuntárias das pálpebras. Espasmo hemifacial (EH), cuja fisiopatologia é distinta do $\mathrm{BE}$, constitui bom grupo controle quando se investiga alterações não-motoras no BE. Objetivo: Comparar o desempenho de pacientes com BE e com EH na Bateria de Avaliação Frontal (BAF). Método: BAF e Mini-Exame do Estado Mental (MEEM) foram administrados a 22 pacientes com BE e 29 com EH. Os escores da BAF foram comparados entre os dois grupos. Correlações entre resultados na BAF e variáveis sócio-demográficas e clínicas foram calculadas. Resultados: Os grupos BE e EH foram semelhantes quanto a gênero, idade, duração dos sintomas, escolaridade e desempenho no MEEM. Os escores dos dois grupos na BAF foram também similares, correlacionando-se negativamente com idade e positivamente com escolaridade e desempenho no MEEM. Conclusão: As funções executivas avaliadas pela BAF não estão alteradas no BE em relação ao EH.

PALAVRAS-CHAVE: distonia, blefaroespasmo, espasmo hemifacial, função executiva.

Dystonia is a syndrome characterized by sustained muscle contractions leading to repetitive twisting movements and abnormal postures. Blepharospasm (BM), one type of focal dystonia, is a disorder characterized by involuntary contractions of the orbicularis oculi muscle with subsequent recurrent and involuntary blinking of the eyes. It is initially characterized by an increased frequency of blinking, but it can become quite disabling and even prog- ress to functional blindness ${ }^{1}$. Although traditionally regarded as a pure movement disorder, several studies have revealed additional non-motor disturbances in focal dystonia, including somatosensory perceptual deficits ${ }^{2}$, visual perceptual deficits ${ }^{3}$, psychiatric disorders ${ }^{4-6}$ and deficits in complex visuospatial tasks ${ }^{7,8}$. While these latter deficits appear to support current models of a disturbed interaction between frontal cortex, basal ganglia, and thalamus

\footnotetext{
Faculdade de Medicina da Universidade Federal de Minas Gerais (UFMG), Belo Horizonte MG, Brazil: 'Médico Psiquiatra, Mestrando em Neurociências; ${ }^{2}$ Fisioterapeuta, Mestranda em Neurociências; ${ }^{3}$ Médico Psiquiatra, Doutorando em Neurociências; ${ }^{4}$ Professor de Neurologia. This work was partly funded by grants from Conselho Nacional de Desenvolvimento Científico e Tecnológico (CNPq).
} 
in focal dystonia, recent studies have yielded conflicting results regarding the occurrence of cognitive impairment in these patients ${ }^{9-11}$. It has been also difficult to determine the specific impact of perceptual, mnemonic and executive cognitive deficits on focal dystonia ${ }^{12,13}$.

Executive functions are mental processes involved in the performance of goal-directed behavior whether expressed through a mental or a motor act ${ }^{14}$. Executive functions are frequently impaired after frontal lobe or basal ganglia damage ${ }^{14}$. The frontal assessment battery (FAB) is a bedside test developed to evaluate executive functioning. It takes less than 10 minutes to administer and a low score indicates executive dysfunction ${ }^{15,16}$.

The aim of this study was to investigate frontal lobe function in patients with BM by examining executive functioning as assessed by the FAB. For comparison, hemifacial spasm (HS) patients were recruited. HS is characterized by non voluntary contractions of the orbicularis oculi muscle and may evolve to compromise other muscles of one half of the face. Although the two conditions are similar in terms of symptoms and subjective impairment, $\mathrm{HS}$ results from peripheral facial nerve damage and is not related to basal ganglia dysfunction ${ }^{17}$. Thus HS constitutes an ideal control group for BM comparison.

\section{METHOD}

Fifty-one patients followed at the Movement Disorders Clinic of the School of Medicine of the Federal University of Minas Gerais (UFMG) were enrolled in this study. Written informed consent was obtained from all patients. The study was approved by the local ethics committee.

Twenty-two BM patients (M/F, 7/15) diagnosed as having primary dystonia, participated in the study. A careful investigation of secondary or symptomatic causes of dystonia was performed. For comparison, twenty-nine patients with HS (M/F, 7/22) were studied. Patients with other neurological diseases were excluded. All patients had been treated with botulinum toxin at least once before inclusion in the study.

Patients were submitted to a complete neurological examination, to the FAB and to the Mini-Mental State Examination (MMSE).

Comparisons of categorical variables between groups were performed by using the Fisher's exact test. For continuous vari- ables, Mann-Whitney U test was carried out. Spearman's rho test was used to assess correlation. All p-values were two tailed and a significance level of 0.05 was chosen. Statistical analysis was performed using the SPSS v15.0 software.

\section{RESULTS}

BM and HS patients did not differ either in demographic or in clinical features (Table). Performance of both groups in $F A B$ was also similar ( $p=0.977)$ (Fig 1).

$F A B$ raw scores ranged from 3 to 18 in $B M$ group and from 5 to 18 in HS group. Although some patients scored extremely low in FAB (Fig 1), no patient was diagnosed with dementia according to clinical criteria and to cutoff scores of MMSE adjusted to the educational level as proposed for Brazilian population ${ }^{18}$.

FAB performance correlated negatively with age ( $r$ o $=-0.348 ; p=0.012$ ), and positively with educational level (rho=0.516; $\mathrm{p}<0.001$ ) and with MMSE performance (rho=0.627; $\mathrm{p}<0.001$ ) (Fig 2).

\section{DISCUSSION}

Executive functioning as assessed by $F A B$ did not differ between BM and HS groups in the present study. This result contrasts with the hypothesis that plastic changes in the frontal lobe following focal dystonia would be

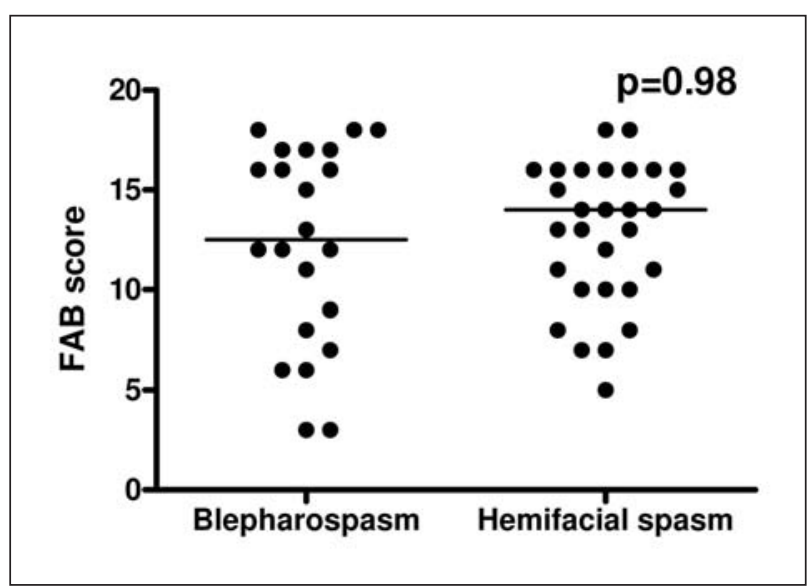

Fig 1. Frontal Assessment Battery (FAB) total scores in patients with blepharospasm and hemifacial spasm. The trace indicates median values.

Table. Comparison between patients with blepharospasm and hemifacial spasm

\begin{tabular}{lccc}
\hline & Blepharospasm & Hemifacial spasm & p values \\
\hline Gender $(\mathrm{M} / \mathrm{F})$ & $7 / 15$ & $7 / 22$ & 0.752 \\
Age, $y$, mean \pm SD & $61.5 \pm 13.7$ & $60.5 \pm 11.7$ & 0.648 \\
Educational level, $y$, mean \pm SD & $6.7 \pm 4.8$ & $5.8 \pm 3.4$ & 0.478 \\
Length of symptoms, $y$, mean \pm SD & $8.4 \pm 4.8$ & $9.1 \pm 4.9$ & 0.985 \\
MMSE, mean $\pm S D$ & $25.3 \pm 3.3$ & $25.8 \pm 2.6$ & 0.985 \\
\hline
\end{tabular}

SD, standard deviation; MMSE, Mini-Mental State Examination. 


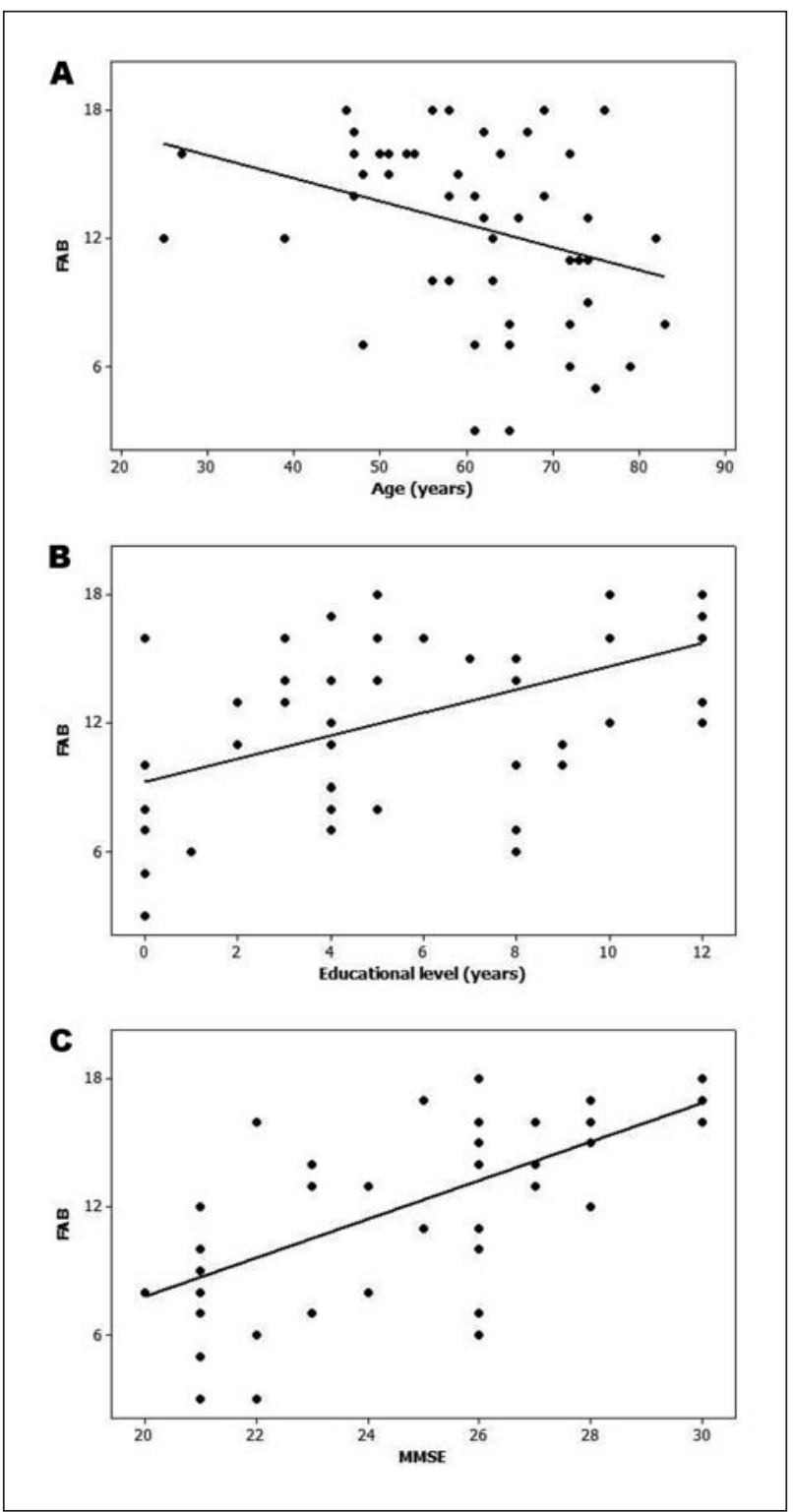

Fig 2. Correlation between Frontal Assessment Battery (FAB) scores and age (years) (A), education level (years) (B) and Mini-Mental State Examination (MMSE) (C).

associated with impaired executive function in these patients ${ }^{19}$

The studies assessing cognition in dystonia have conflicting results. While Jahanshahi et al. demonstrated that patients with idiopathic dystonia did not present deficits in executive function or working memory ${ }^{12}$, Scott et al. observed significant deficits in attentional-executive cognitive domains ${ }^{13}$. Despite the small number of patients in both studies, most patients assessed by Scott et al. had generalized dystonia ${ }^{13}$, while the sample of Jahanshahi et al. was more heterogeneous ${ }^{12}$. Vermilion et al. found that patients with cervical dystonia with tremor had more cognitive impairment in tasks requiring attention ${ }^{20}$, while patients with cervical dystonia without tremor had more impairment in executive function ${ }^{21}$. Thus, it is possible that patients with different types of dystonia differ in their cognitive functioning.

Previous studies have suggested cut-off scores on the FAB for screening dysexecutive syndromes. Slachevsky et al. showed that a cut-off score of 12 was optimal to discriminate frontotemporal dementia from Alzheimer's disease $^{22}$. Appollonio et al. suggested that FAB scores equal or lower than 13.5 could be considered abnormal in an Italian population ${ }^{23}$. In our study, the mean values in FAB (12.3 \pm 4.9 and $12.8 \pm 3.5$ for $B M$ and $\mathrm{HS}$, respectively) were low and in the cut-off range as reported in these previous studies, and similar to the scores observed by Beato et al. in cognitively healthy Brazilian elderly ${ }^{16}$. However, no patient presented a performance on MMSE suggestive of cognitive decline or dementia.

Dubois et al. did not find any correlation between MMSE and $F A B^{15}$. These authors explained this result by stating that MMSE was not sensitive for impairment in executive functions. By contrast, our study showed significant correlation between FAB and MMSE. This feature was also reported by Lipton et al. ${ }^{24}$ and Beato et al. ${ }^{16}$. Maybe educational level can interfere in the performance in the FAB as it occurs with the MMSE. However, this hypothesis could not explain the findings from Lipton et al., as their sample did not differ in educational level from the one evaluated by Dubois et al. In this former study, the authors suggested that mental flexibility, motor programming, and environmental autonomy were more sensitive to executive dysfunction than total FAB score ${ }^{24}$.

In our study, FAB scores were also influenced by age, but this could be explained by the fact that old people in Brazil had less opportunity of formal education. Indeed, educational level and age correlated negatively (data not shown).

Although the worse performance in this Brazilian sample may be partially explained by the significant influence exerted by education on the FAB, scores in the battery could also be predicted by the performance in a general test of cognition, such as the MMSE. Further work must investigate the diagnostic accuracy of the $F A B$ in specific populations with low levels of education.

In conclusion, executive function as assessed by FAB was not disturbed in BM. The performance on FAB correlates with educational level and MMSE.

\section{REFERENCES}

1. Carvalho Aguiar PM, Ozelius LJ. Classification and genetics of dystonia. Lancet Neurol 2002;1:316-325.

2. Tinazzi M, Rosso T, Fiaschi A. Role of the somatosensory system in primary dystonia. Mov Disord 2003;18:605-622.

3. Büttner T, Kuhn W, Dietz M, et al. Impaired visual function in focal idiopathic dystonia. Eur Neurol 1999;41:94-98.

4. Kubota Y, Murai T, Okada T, et al. Obsessive-compulsive character- 
istics in patients with writer's cramp. J Neurol Neurosurg Psychiatry 2001;71:413-414.

5. Bihari K, Hill JL, Murphy DL. Obsessive-compulsive characteristics in patients with idiopathic spasmodic torticollis. Psychiatric Res 1992;42:267-272.

6. Gündel H, Wolf A, Xidara V, et al. High psychiatric comorbidity in spasmodic torticollis: a controlled study. J Nerv Ment Dis 2003;191:465-473.

7. Leplow B, Stübinger C. Visuospatial functions in patients with spasmodic torticollis. Percept Mot Skills 1994;78:1363-1375.

8. Hinse P, Leplow B, Humbert T, Lamparter U, Junge A, Emskötter T. Impairment of visuospatial function in idiopathic spasmodic torticollis. J Neurol 1996;243:29-33.

9. Berardelli A, Rothwell JC, Hallet M, Thompson PD, Manfredi M, Marsden CD. The pathophysiology of primary dystonia: a neuronal model. Brain 1998;121:1195-1212.

10. Dauer WT, Burke RE, Greene P, Fahn S. Current concepts on the clinical features, aetiology and management of idiopathic cervical dystonia. Brain 1998;121(Pt 4):547-560.

11. Vitek JL. Pathophysiology of dystonia;a neuronal model. Mov Disord 2002;17(Suppl 3):S49-S52.

12. Jahanshahi M, Rowe J, Fuller R. Cognitive executive function in dystonia. Mov Disord 2003;18:1470-1481.

13. Scott RB, Gregory R, Wilson J, et al. Executive cognitive deficits in primary dystonia. Mov Disord 2003;18:539-550.

14. Lezak MD. Executive functions and motor performance. In: Lezak MD, Howieson DB, Loring DW (Eds). Neuropsychological assesment. $4^{\text {th }}$ ed. New York: Oxford University Press 2004:611-646.
15. Dubois B, Slachevsky A, Litvan I, Pillon B. The FAB: a frontal assessment battery at bedside. Neurology 2000;55:1621-1626.

16. Beato RG, Nitrini R, Formigoni AP, Caramelli P. Brazilian version of the Frontal Assessment Battery (FAB): preliminary data on administration to healthy elderly. Dementia \& Neuropsychologia 2007;1:59-65.

17. Nielsen VK. Pathophysiology of hemifacial spasm, I: ephaptic transmission and ectopic excitation. Neurology 1984;34:418-426.

18. Brucki SM, Nitrini R, Caramelli P, Bertolucci PH, Okamoto IH. Suggestions for utilization of the mini-mental state examination in Brazil. Arq Neuropsiquiatr 2003;61:777-781.

19. Dresel C, Haslinger B, Castrop F, Wohlschlaeger AM, Ceballos-Baumann AO. Silent event-related fMRI reveals deficient motor and enhanced somatosensory activation in orofacial dystonia. Brain 2006;129:36-46.

20. Vermilion K, Peterson J, Duane D. Cognition and affect in patients with cervical dystonia without tremor. Mov Disord 2002;17(Suppl. 5):S281.

21. Vermilion K, Johnson J, Duane D. Cognition and affect in patients with cervical dystonia and tremor. Mov Disord 2002;17:1138.

22. Slachevsky A, Villalpando JM, Sarazin M, Hahn-Barma V, Pillon B, Dubois B. Frontal assessment battery and differential diagnosis of frontotemporal dementia and Alzheimer disease. Arch Neurol 2004;61: 1104-1107.

23. Appollonio I, Leone M, Isella V, et al. The Frontal Assessment Battery (FAB): normative values in an Italian population sample. Neurol Sci 2005;26:108-116

24. Lipton AM, Ohman KA, Womack KB, Hynan LS, Ninman ET, Lacritz $\mathrm{LH}$. Subscores of the FAB differentiate frontotemporal lobar degeneration from AD. Neurology 2005;65:726-731 